\title{
Selecting a $k-\varepsilon$ turbulence model for investigating n-decane combustion in a diesel engine combustion chamber
}

\author{
Andrii N. Avramenko \\ A. Podgorny Institute for Mechanical Engineering Problems of the National Academy of Sciences \\ of Ukraine, Str. Pozharskogo, 2/10, 61046 Kharkiv, Ukraine \\ an0100@ukr.net
}

Keywords: n-decane combustion, turbulence model, toxic substances, diesel engine, ecological indicators.

The results of a comparative numerical simulation of combustion and formation of toxic substances in a diesel engine combustion chamber are given. Experimental findings were used to identify the mathematical models. The impact of the standard, RNG and realizable $k$ - $\varepsilon$ turbulence models on the accuracy of numerical simulation of combustion and the formation of toxic substances was studied. The realizable $k-\varepsilon$ turbulence model was shown to provide a closer agreement of computational and experimental data during simulation of the diesel engine process when turbulent flows are described.

\section{Introduction}

The development of numerical simulation techniques makes it possible to simulate combustion and the formation of toxic substances in an engine cylinder with a high level of accuracy and confidence $[1,2]$. The features of combustion in a diesel engine are the alternating high local concentrations of fuel and oxidizer, a small cycle time and the essential impact of the mixture formation method on engine performance [3-5]. By proper selection of a model for describing turbulent flows in an engine cylinder more accurate and valid numerical simulation results can be obtained.

Conventionally, three main mixture formation methods are distinguished in diesel engines: voluminal (all the fuel is vaporized and ignited within the volume of the heated oxidizer), voluminal-filmy (a fraction of the fuel ends up on the walls of the parts of the combustion chamber, vaporizes and ignites) and filmy (during injection all the fuel ends up on the walls of the combustion chamber).

Advanced software packages serve for simulating the processes of mixture formation, combustion and formation of toxic substances in the plane axisymmetric and three-dimensional statements [6-8]. Chemical mechanisms, for instance, those implemented in the CHEMKIN package, are used for a detailed description of fuel combustion kinetics [9].

Not well understood yet are problems related to selecting and setting up mathematical models for investigating rapidly changing cyclic 
processes of mixture formation, and combustion and formation of toxic substances in the combustion chambers of engines, especially diesel ones, with account of the specific features of how the mixture formation process is managed.

\section{Experimental part}

Experimental research was conducted on a test bench with the D21A diesel engine in the laboratory of the A. Podgorny Institute for Mechanical Engineering Problems NAS of Ukraine. The brief specifications of the diesel engine are given in Table 1.

Table 1.Brief specification of diesel engine

\begin{tabular}{|c|l|c|}
\hline $\begin{array}{c}\text { Item } \\
\text { No. }\end{array}$ & \multicolumn{1}{|c|}{ Parameter } & Value \\
\hline 1 & Rated power, $\mathrm{kW}$ & 18.4 \\
\hline 2 & $\begin{array}{l}\text { Rotational speed corresponding to } \\
\text { rated power conditions, } \text { min }^{-1}\end{array}$ & 1800 \\
\hline 3 & Cylinder diameter, mm & 105 \\
\hline 4 & Piston stroke, mm & 120 \\
\hline 5 & Compression ratio & 16.5 \\
\hline 6 & $\begin{array}{l}\text { Number of holes in the injector } \\
\text { nozzle }\end{array}$ & 3 \\
\hline 7 & $\begin{array}{l}\text { Diameter of injector nozzle holes, } \\
\text { mm }\end{array}$ & 0.3 \\
\hline
\end{tabular}

The following physical parameters were controlled during the experiment: fuel and air consumption, exhaust temperature, exhaust toxicity (a 5-component gas analyzer was used), and indicator diagrams were plotted (pressure variation in the engine cylinder). The temperature of combustion chamber parts (piston-continuous current pickup and the cylinder head) was also controlled.
Next, numerical techniques were used for a comparative computational study in evaluating the impact of different $k-\varepsilon$ turbulence models on the accuracy of simulating the diesel engine process.

The study used the finite volume method for numerical simulation of processes in the engine combustion chamber.

The computational grid for numerical simulation is shown in Figure 1.

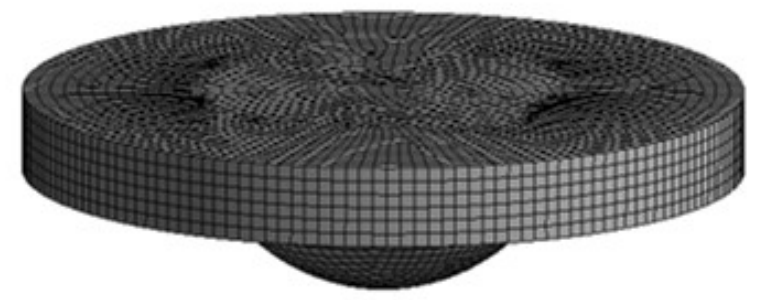

Figure 1.Computational grid (25100 computational cells)

The fuel combustion process (owing to short-duration fuel combustion in a diesel engine) can be calculated using the following dependence:

$$
\begin{aligned}
& \mathrm{CH}_{n}+\frac{\alpha_{s}}{\phi} \cdot\left(\mathrm{O}_{2}+3.78 \mathrm{~N}_{2}\right) \rightarrow \mathrm{CO}_{2}+ \\
& +\frac{n}{2} \cdot \mathrm{H}_{2} \mathrm{O}+\alpha_{s}\left(\frac{1}{\phi}-1\right) \cdot \mathrm{O}_{2}+\frac{3.78 \alpha_{s}}{\phi} \cdot N_{2},
\end{aligned}
$$

where $\alpha_{s}=1+n / 4$ and the equivalence ratio $\phi$, is the fuel to air ratio normalized to the stoichiometric fuel to air ratio.

The standard $k-\varepsilon$ model equations have the form:

$$
\frac{\partial}{\partial t}(\rho \cdot k)+\frac{\partial}{\partial x_{i}}\left(\rho \cdot k \cdot \bar{u}_{i}\right)=\frac{\partial}{\partial x_{j}}\left[\left(\mu+\frac{\mu_{t}}{\sigma_{k}}\right) \frac{\partial k}{\partial x_{j}}\right]+
$$




$$
\begin{aligned}
& +G_{k}+G_{b}-\rho \cdot \varepsilon-Y_{M}+S_{k}, \\
& \frac{\partial}{\partial t}(\rho \cdot \varepsilon)+\frac{\partial}{\partial x_{i}}\left(\rho \cdot \varepsilon \cdot \bar{u}_{i}\right)=\frac{\partial}{\partial x_{j}}\left[\left(\mu+\frac{\mu_{t}}{\sigma_{\varepsilon}}\right) \frac{\partial \varepsilon}{\partial x_{j}}\right]+ \\
& +G_{1 \varepsilon} \frac{\varepsilon}{k}\left(G_{k}+C_{3 \varepsilon} \cdot G_{b}\right)-C_{2 \varepsilon} \cdot \rho \frac{\varepsilon^{2}}{k}+S_{\varepsilon} .
\end{aligned}
$$

$\mathrm{k}$ is specific kinetic turbulent energy; $\varepsilon$ is rate of viscous dissipation of turbulent energy; $\rho$ is gas density; $\mu_{t}$ is turbulent dynamic viscosity; $\bar{u}_{i}$ is averaged velocity; $\sigma_{k}$ is a dimensionless empirical constant; $G_{k}$ is turbulent kinetic energy formed by mean velocity gradients; $G_{b}$ is displacement force kinetic energy; $C_{3 \varepsilon}, C_{2 \varepsilon}$ are constants; $Y_{M}$ is the contribution of the variable expansion during compression turbulence to the total dissipation rate; $S_{k}$ is invariant of the strain tensor.

The RNG $k-\varepsilon$ turbulence model differs from the standard one by the following features: - it has an additional term for $\varepsilon$, which improves the computational accuracy for a fluid with high deformation rates;

- the model accounts for the vorticity impact on turbulence to increase computational accuracy; - it offers analytical formulae for Prandtl turbulence numbers, whereas the standard $k$ $\varepsilon$ model uses standard values.

The RNG $k-\varepsilon$ model equations have the following form:

$$
\begin{aligned}
& \frac{\partial}{\partial t}(\rho \cdot k)+\frac{\partial}{\partial x_{i}}\left(\rho \cdot k \cdot \bar{u}_{i}\right)=\frac{\partial}{\partial x_{j}}\left(\alpha_{k} \cdot \mu_{e f f} \frac{\partial k}{\partial x_{j}}\right)+ \\
& +G_{k}+G_{b}-\rho \cdot \varepsilon-Y_{M}+S_{k},
\end{aligned}
$$

$$
\begin{aligned}
& \frac{\partial}{\partial t}(\rho \cdot \varepsilon)+\frac{\partial}{\partial x_{i}}\left(\rho \cdot \varepsilon \cdot \bar{u}_{i}\right)=\frac{\partial}{\partial x_{j}}\left(\alpha_{\varepsilon} \cdot \mu_{e f f} \frac{\partial \varepsilon}{\partial x_{j}}\right)+ \\
& +G_{1 \varepsilon} \frac{\varepsilon}{k}\left(G_{k}+C_{3 \varepsilon} \cdot G_{b}\right)-C_{2 \varepsilon} \cdot \rho \frac{\varepsilon^{2}}{k}-R_{\varepsilon}+S_{\varepsilon} .
\end{aligned}
$$

The main feature that distinguishes the RNG $k-\varepsilon$ model from the standard one is the presence of an additional term in the equation for $\varepsilon:$

$$
R_{\varepsilon}=\frac{C_{\mu} \cdot \rho \cdot \eta^{3}\left(1-\frac{\eta}{\eta_{0}}\right) \varepsilon^{2}}{1+\beta \cdot \eta^{3}} \frac{\varepsilon^{2}}{k}
$$

The realizable $k-\varepsilon$ model, as compared with the standard one, has two differences:

- the realizable $k-\varepsilon$ model has an alternative formulation for turbulent viscosity;

- the modified transport equation for dissipation rate $\varepsilon$ is derived from the exact transport equation for r.m.s. vorticity oscillations.

The equations for a realizable $k$ - $\varepsilon$ model have the form:

$$
\frac{\partial}{\partial t}(\rho \cdot k)+\frac{\partial}{\partial x_{i}}\left(\rho \cdot k \cdot \bar{u}_{i}\right)=\frac{\partial}{\partial x_{j}}\left[\left(\mu+\frac{\mu_{t}}{\sigma_{k}}\right) \frac{\partial k}{\partial x_{j}}\right]+
$$$$
+G_{k}+G_{b}-\rho \cdot \varepsilon-Y_{M}+S_{k},
$$

$$
\begin{aligned}
& \frac{\partial}{\partial t}(\rho \cdot \varepsilon)+\frac{\partial}{\partial x_{i}}\left(\rho \cdot \varepsilon \cdot \bar{u}_{i}\right)=\frac{\partial}{\partial x_{j}}\left[\left(\mu+\frac{\mu_{t}}{\sigma_{\varepsilon}}\right) \frac{\partial \varepsilon}{\partial x_{j}}\right]+ \\
& +\rho \cdot C_{1} \cdot S_{\varepsilon}-\rho \cdot C_{2} \frac{\varepsilon^{2}}{k+\sqrt{v \cdot \varepsilon}}+C_{1 \varepsilon} \frac{\varepsilon}{k} C_{3 \varepsilon} \cdot G_{b}+S_{\varepsilon}
\end{aligned}
$$

In this study, the processes of formation of monoxide nitrogen (NO) were simulated using the thermal mechanism suggested by Ya.B. Zeldovich and Fenimore's mechanism of the socalled prompt NO [10-12]. 
The formation of thermal NO comprises

a three-stage mechanism:

$$
\begin{aligned}
& \mathrm{O}+\mathrm{N}_{2} \leftrightarrow \mathrm{NO}+\mathrm{N} \\
& \mathrm{N}+\mathrm{O}_{2} \leftrightarrow \mathrm{NO}+\mathrm{O} \\
& \mathrm{OH}+\mathrm{N} \leftrightarrow \mathrm{NO}+\mathrm{H} .
\end{aligned}
$$

The formation of NO by the prompt NO mechanism has the form:

$$
\begin{aligned}
& \mathrm{CH}+\mathrm{N}_{2}=\mathrm{HCN}+\mathrm{N} \\
& 2 \mathrm{C}+\mathrm{N}_{2}=2 \mathrm{CN} \\
& \mathrm{CH}_{2}+\mathrm{N}_{2}=\mathrm{NC}+\mathrm{NH} .
\end{aligned}
$$

Diesel fuel is known to be a mix of hydrocarbons of different chemical groups. In the paper, with account of recommendations of authors [13-15], fuel combustion in the combustion chamber is simulated using n-decane $\left(\mathrm{C}_{10} \mathrm{H}_{22}\right)$ as an analog of diesel fuel.

\section{Results}

Comparative numerical simulation results are shown in Figures 2- 6.

Figure 2 is the graph of the comparison of pressure variation in the diesel engine combustion chamber vs. crankshaft rotation angle (piston position). The crankshaft angle was within 225 to 425 degrees.

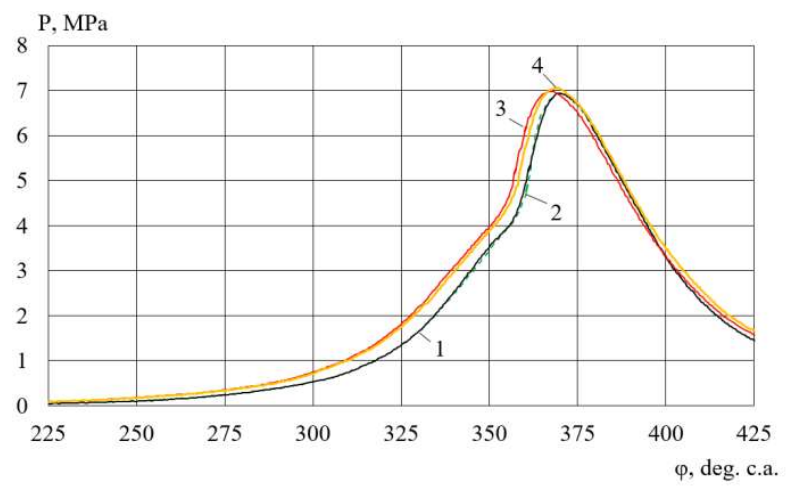

1 - standard $k-\varepsilon$ model; 2 - RNG $k-\varepsilon$ model; 3 - realizable $k-\varepsilon$ model; 4 - experiment
Figure 2. Pressure in the diesel engine combustion chamber vs. crankshaft angle

Figure 2 shows that the realizable $k-\varepsilon$ turbulence model provides more accurate results as compared to experimental data.

Figure 3 shows the variation of the volume-averaged temperature in the diesel engine cylinder.

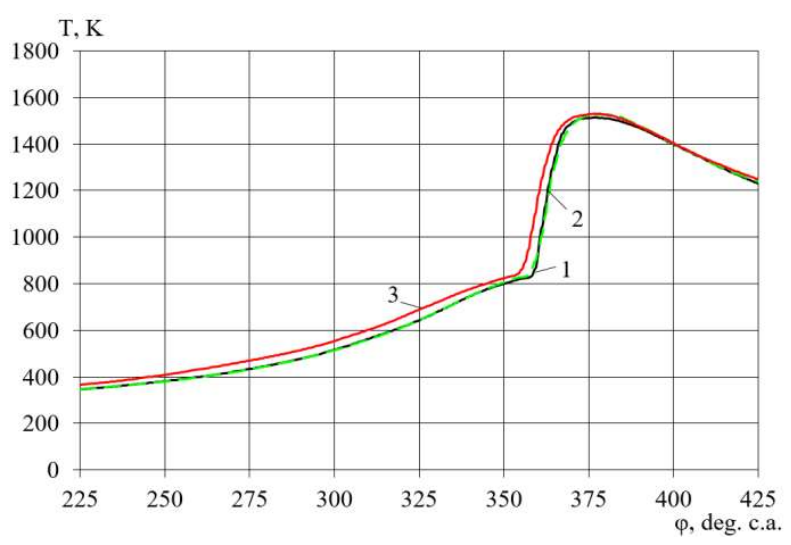

1 - standard $k-\varepsilon$ model; 2 - RNG $k$ - $\varepsilon$ model; 3 - realizable

$$
k-\varepsilon \text { model }
$$

Figure 3. Temperature in diesel engine cylinder vs. crankshaft angle

As the results demonstrate, the realizable $k-\varepsilon$ turbulence model used in the experiment yields more accurate numerical simulation data.

The local values of temperature, gas and flame velocity, and NO mass fraction as a function of the used $k-\varepsilon$ turbulence models are shown in Figure 4-6.

Figure 4 shows the results of computing combustion and NO formation for a standard $k-\varepsilon$ turbulence model. 


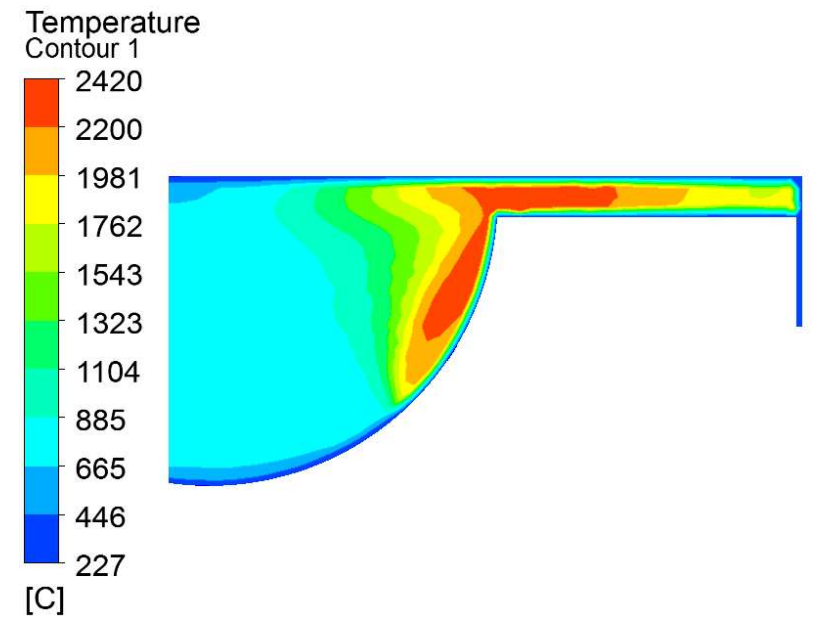

a)

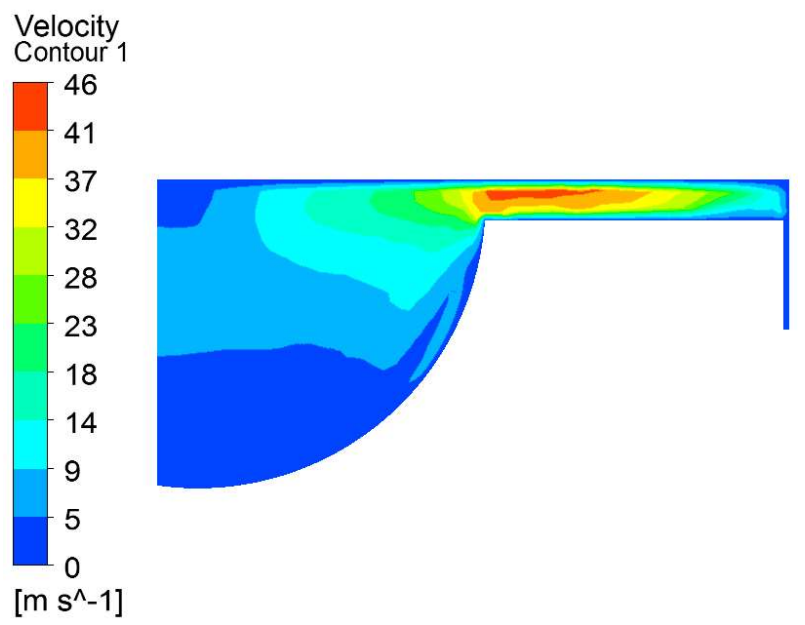

b)

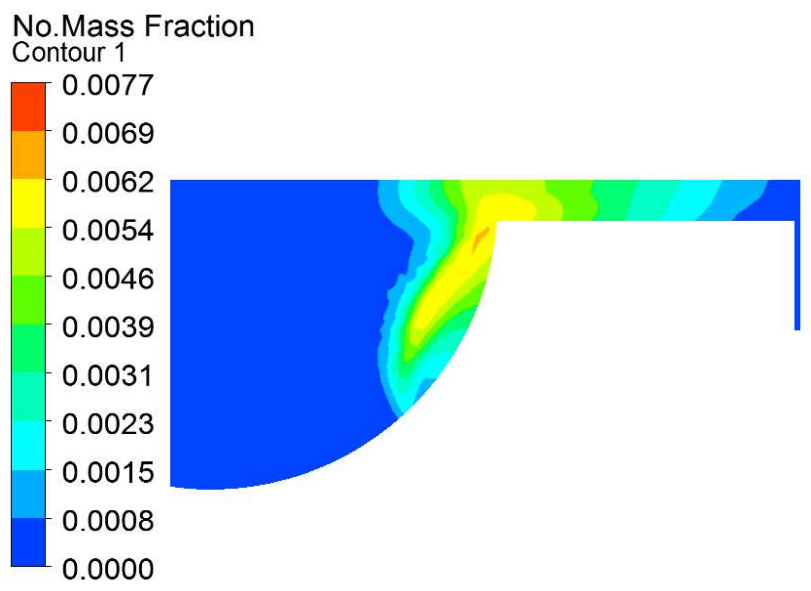

c)

Figure 4. Local values of temperature (a), velocity (b) and mass fraction NO (c) in the meridional section of the combustion chamber (standard $k-\varepsilon$ turbulence model)
As Figure 4 shows, the maximum local estimated temperature is $2,420 \mathrm{~K}$, the maximum local gas and flame velocity is $46 \mathrm{~m} / \mathrm{s}$, and the local NO mass fraction is up to 0.0077 .

Figure 5 shows the results of computing combustion and NO formation for the RNG $k-\varepsilon$ turbulence model.

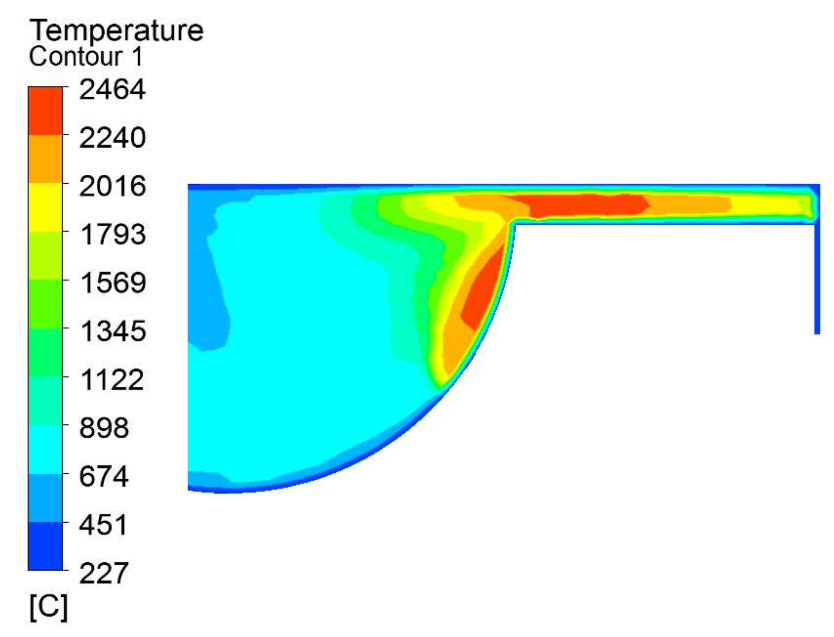

a)
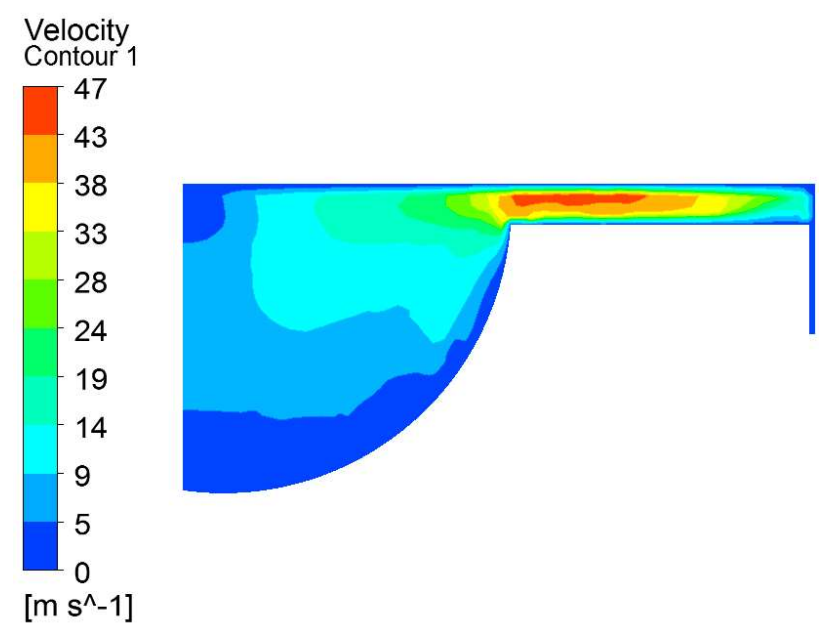

b) 
No.Mass Fraction

Contour 1

0.0070

0.0063

0.0056

0.0049

0.0042

0.0035

0.0028

0.0021

0.0014

0.0007

0.0000

c)

Figure 5. Local values of temperature (a), velocity (b) and mass fraction NO (c) in the meridional section of the combustion chamber (RNG $k-\varepsilon$ turbulence model)

As Figure5 shows, the maximum local estimated temperature is $2,464 \mathrm{~K}$, the maximum local gas and flame velocity is $47 \mathrm{~m} / \mathrm{s}$, and the local NO mass fraction is up to 0.007 .

Figure 6 shows the results of computing combustion and NO formation for the realizable $k-\varepsilon$ turbulence model.

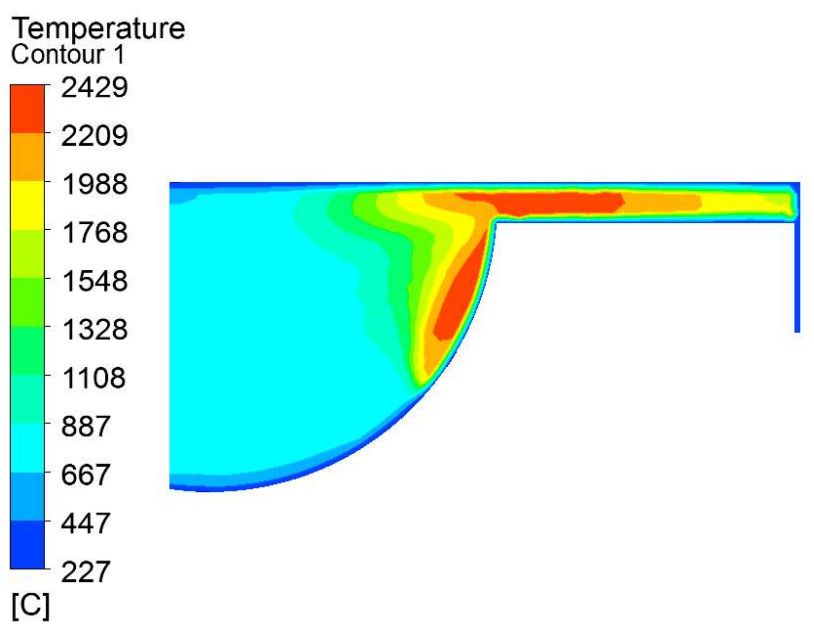

a)
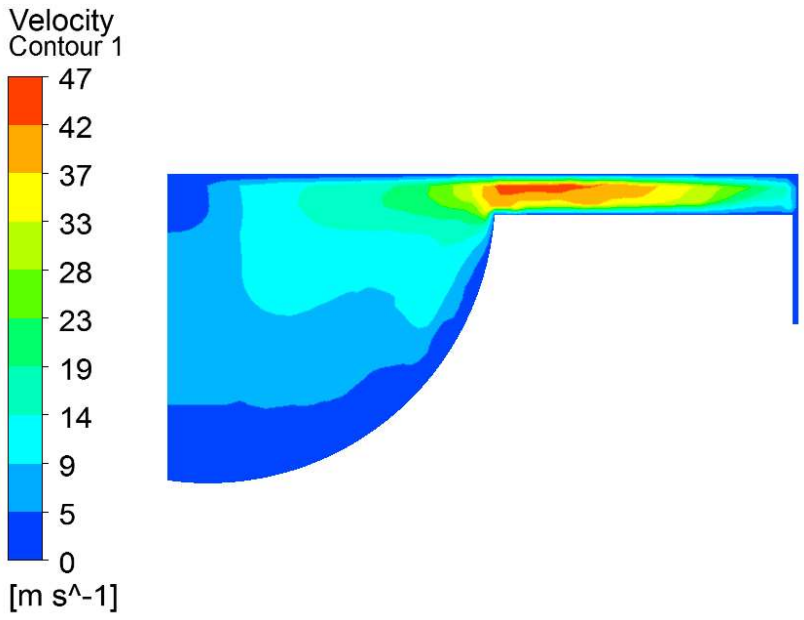

$\left[\mathrm{m} \mathrm{s} \mathrm{s}^{\wedge}-1\right]$

b)

No.Mass Fraction
Contour 1

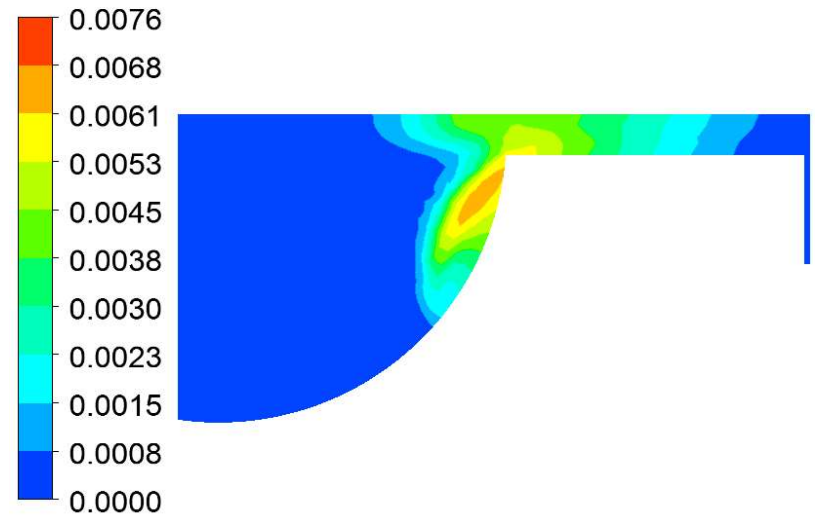

c)

Figure 6. Local values of temperature (a), velocity (b) and mass fraction NO (c) in the meridional section of the combustion chamber (realizable $k-\varepsilon$ turbulence model)

As Figure 6 shows, the maximum local estimated temperature is $2,429 \mathrm{~K}$, the maximum local gas and flame velocity is $47 \mathrm{~m} / \mathrm{s}$, and the local NO mass fraction is up to 0.0076 .

\section{Discussion}

Table 2 shows the summarized results of experimental and numerical research. 
Table 2.Summarised research results (operating duty with $\mathrm{n}=1,400 \mathrm{~min}^{-1}$ ).

\begin{tabular}{|l|c|c|c|}
\hline Parameter & $\mathrm{P}_{\mathrm{z}}$ & $\mathrm{T}_{\mathrm{ex}}$ & $\mathrm{NO}_{\mathrm{x}}$ \\
\hline Units & $\mathrm{MPa}$ & ${ }^{\circ} \mathrm{C}$ & $\mathrm{ppm}$ \\
\hline Experiment & 7,065 & 646 & 1643 \\
\hline \multicolumn{3}{|c|}{ Calculation } \\
\hline
\end{tabular}

(different $k$ - $\varepsilon$ turbulence models):

\begin{tabular}{|l|c|c|c|}
\hline Standard & 6,93 & 642 & 1470 \\
\hline RNG & 6,92 & 640 & 1495 \\
\hline Realizable & 7,04 & 650 & 1596 \\
\hline
\end{tabular}

$\mathrm{n}$ - crankshaft rotation speed;

$\mathrm{P}_{\mathrm{Z}}-$ maximum combustion pressure;

$\mathrm{T}_{\mathrm{ex}}$ - exhaust temperature.

The summarised results in Table 2 show that numerical techniques yield a close agreement of computational and experimental data when simulating n-decane combustion processes in a diesel engine combustion chamber. The realizable $k-\varepsilon$ turbulence model provides for the most accurate description of combustion and NO formation for a diesel engine with voluminal-filmy mixture formation.

\section{Conclusions}

The study findings allow for drawing the following conclusions:

- using n-decane fuel instead of diesel fuel for numerical simulation of a diesel engine process produces fairly accurate and meaningful data;

- unrealizable $k$ - $\varepsilon$ turbulence model describes the process of $n$-decane combustion in a diesel engine combustion chamber more accurately;
- the Zeldovich thermal mechanism and Fenimore's mechanism used for simulating the processes of formation of monoxide nitrogen in a diesel engine combustion chamber yield a close agreement of experimental and computational data.

\section{References}

[1] Reitz R., Duraisamy G. Review of high efficiency and clean reactivity controlled compression ignition (RCCI) combustion in internal combustion engines. Progress in Energy and Combustion Science. 2015; 46: 12-71.

https://doi.org/10.1016/j.pecs.2014.05.003

[2] Lia Y.,Jia M., Chang Y., Kokjohn S., Reitz R. Thermodynamic energy and exergy analysis of three different engine combustion regimes. Applied Energy. 2016; 180: 849-858.

https://doi.org/10.1016/j.apenergy.2016.08.038

[3] Patrylak L., Patrylak K., Okhrimenko M., Zubenko S., Levterov A.,Savytskyi V. Comparison of Power-Ecological Characteristics of Diesel Engine Work on Mixed Diesel Fuels on the Basis of Ethyl Estersof Rapeseed and Sunflower Oils. Chemistry \& Chemical Technology. 2015; 9:383-

390.https://doi.org/10.23939/chcht09.03.383

[4] Patrylak L.,Patrylak K., Okhrimenko M., Ivanenko V., Zubenko S.,Levterov A., Marakhovskyi V., Savytskyi V. Ethanol containing ethyl esters of fatty acids as perspective environment like fuel. Fuel. 2013; 113:650653.

https://doi.org/10.1016/j.fuel.2013.06.020

[5] Girish B., Neeraj S., Suryawanshi J. Investig ations on Premixed Charge Compression Ignition (PCCI) Engines: A Review. 2017. https://doi.org/10.1007/978-81322-2743-4_139.

[6] Perini F., Zha K., Busch S., Reitz R. Comparison of Linear, Non-Linear and Generalized RNGBased k-epsilon Models for Turbulent Diesel Engine Flows. 2017 
https://doi.org/10.4271/2017-01-0561.

[7] Dempsey A., Walker N., Reitz R. Effect of Piston Bowl Geometry on Dual Fuel Reactivity Controlled Compression Ignition (RCCI) in a Light-Duty Engine Operated with Gasoline/Diesel and Methanol/Diesel. SAE International Journal of Engines. 2013; 6(1): 78-100. Retrieved from http://www.jstor.org/stable/26277600

[8] Morgan R., Wray J., Kennaird D., Crua C., Heikal M. The influence of injector parameters on the formation and break up of a diesel spray. 2001 SAE Transactions - Journal of Engines. 110(3): 389-399.

[9] Zang R., Yao C. Numerical Study of Combustion and Emission Characteristics of a Diesel/Methanol Dual Fuel (DMDF) Engine. Energy \& Fuels. 2015; 29(6): 3963-3971.

https://doi.org/10.1021/acs.energyfuels.5b00644

[10] Zeldovich Y., Barenblatt G., Librovich V., Makhviladze G. The Mathematical Theory of Combustion and Explosion, Consultants Bureau, New York, NY, USA, 1985.

[11] Herbinet O., Pitz W., Westbrook C. Detailed chemical kinetic oxidation mechanism for a biodiesel surrogate. Combustion and Flame. 2008;154 (3): 507-528,

[12] Williams B., Sutton J., Fleming J. The role of methylene in prompt NO formation. Proceedings of the Combustion Institute. 2009; 32(1): 343-350.

[13] Battin-Leclerc F. Detailed chemical kinetic models for the low-temperature combustion of hydrocarbons with application to gasoline and diesel fuel surrogates. Progress in Energy and Combustion Science. 2008; 34: 440-498.

https://doi.org/10.1016/j.pecs.2007.10.002

[14] Moréac G., Blurock E., Mauss F. Automatic generation of a detailed mechanism for the oxidation of ndecane. Combustion Science and Technology. 2006; 178:2025-2038.

https://doi.org/10.1080/00102200600793262

[15] Buda F., Bounaceur R., Warth V., Glaude P., Fournet R., Battin-Leclerc F. Progress towards an unified detailed kinetic model for the autoignition of alkanes from
$\mathrm{C}_{4}$ to $\mathrm{C}_{10}$ between 600 and $1200 \mathrm{~K}$. Combustion and Flame. 2005; 142:170-86.

https://doi.org/10.1016/j.combustflame.2005.03.005 